Check for updates

Cite this: RSC Adv., 2019, 9, 16784

\title{
A new iron-based metal-organic framework with enhancing catalysis activity for benzene hydroxylation $\uparrow$
}

\author{
Thach N. Tu, (D)*ab Hue T. T. Nguyen, bc Huong T. D. Nguyen, (D) ${ }^{c}$ My V. Nguyen, (D) \\ Trinh D. Nguyen, (D) ${ }^{a}$ Nhung Thi Tran ${ }^{d}$ and Kwon Taek Lim (D) \\ A new Fe-based metal-organic framework (MOF), termed Fe-TBAPy $\mathrm{Fe}_{2}(\mathrm{OH})_{2}(\mathrm{TBAPy}) \cdot 4.4 \mathrm{H}_{2} \mathrm{O}$, was \\ solvothermally synthesized. Structural analysis revealed that Fe-TBAPy is built from $\left[\mathrm{Fe}(\mathrm{OH})\left(\mathrm{CO}_{2}\right)_{2}\right]_{\infty}$ rod- \\ shaped SBUs (SBUs = secondary building units) and 1,3,6,8-tetrakis( $p$-benzoate)pyrene (TBAPy ${ }^{4-}$ ) linker \\ to form the frz topological structure highlighted by $7 \AA$ channels and $3.4 \AA$ narrow pores sandwiching \\ between the pyrene cores of $\mathrm{TBAPy}^{4-}$. Consequently, Fe-TBAPy was used as a recyclable \\ heterogeneous catalyst for benzene hydroxylation. Remarkably, the catalysis reaction resulted in high \\ phenol yield and selectivity of $64.5 \%$ and $92.9 \%$, respectively, which are higher than that of the other Fe- \\ based MOFs and comparable with those of the best-performing heterogeneous catalysts for benzene \\ hydroxylation. This finding demonstrated the potential for the design of MOFs with enhancing catalysis \\ activity for benzene hydroxylation.
}

Received 2nd May 2019

Accepted 17th May 2019

DOI: $10.1039 / c 9 r a 03287 h$

rsc.li/rsc-advances

the quantitative yield of phenol..$^{\mathbf{1 0} 11}$ Indeed, this could be

\section{Introduction}

Phenol is an important chemical for the production of bakelite and phenolic resins. Currently, the global production of phenol is over 7.2 megatons per year. ${ }^{\mathbf{1 , 2}}$ Traditionally, phenol is produced from benzene by three-step cumene process, which suffers low yield $(\sim 5 \%),{ }^{3}$ high energy consumption, ${ }^{4}$ and generates the explosive cumene hydroperoxide intermediate, ${ }^{1}$ as well as the unnecessary by-products (e.g. acetone, $\alpha$-methylstyrene). ${ }^{5}$ Recently, significant efforts have been devoted to developing the greener and safer one-step hydroxylation protocol for production of phenol from benzene. ${ }^{6}$ In this regard, various catalysts have been used; however, the phenol yields are low for most catalytic systems, for examples FeOCl (43.5\%); ${ }^{1}$ VPO@GO (32.8\%); ${ }^{7} \mathrm{Fe}-\mathrm{ZSM}-5$ (22.9\%); ${ }^{8} \mathrm{Cu}_{2} \mathrm{O}-8 / \mathrm{dG}(19.2 \%)^{9}$ (see ESI, Table S $3 \dagger$ ). On the contrary, only a few examples showed

${ }^{a}$ Nguyen Tat Thanh University, 300A Nguyen Tat Thanh Street, District 4, Ho Chi Minh City 755414, Vietnam. E-mail: tnthach@ntt.edu.vn

${ }^{b}$ Center for Innovative Materials and Architectures (INOMAR), Vietnam National University-Ho Chi Minh (VNU-HCM), Ho Chi Minh City 721337, Vietnam. E-mail: tnthach@inomar.edu.vn

'University of Science, Vietnam National University-Ho Chi Minh (VNU-HCM), Ho Chi Minh City 721337, Vietnam

${ }^{d}$ Ho Chi Minh City University of Technology and Education, 01 Vo Van Ngan Street, Linh Chieu Ward, Thu Duc District, Ho Chi Minh City 720100, Vietnam

${ }^{e}$ Department of Display Engineering, Pukyong National University, Busan, 608-737, South Korea

$\dagger$ Electronic supplementary information (ESI) available: Full synthesis and characterization, crystallographic data, catalysis study of Fe-TBAPy. See DOI: $10.1039 / \mathrm{c} 9 \mathrm{ra} 03287 \mathrm{~h}$ attributed to the fact that phenol is more reactive toward oxidation than benzene. ${ }^{6}$

Metal-organic frameworks (MOFs) are a new class of porous extended materials assembled from well-defined inorganic and organic building units, which link together by strong bonds to shape the periodic structure. Attributing to the flexibility in choosing the building blocks, various MOFs with adjustable pore sizes and shapes as well as tunable internal chemical environments are designed and synthesized. ${ }^{\mathbf{1 2}}$ Up to now, a vast number of MOFs are synthesized and used in a wide range of applications including but not limited to gas and vapour storage/separation, ${ }^{13-15}$ proton conduction, ${ }^{\mathbf{1 6 - 1 8}}$ catalysis, ${ }^{\mathbf{1 9 , 2 0}}$ sensing, ${ }^{\text {21-23 }}$ and drug delivery. ${ }^{\mathbf{2 4 2 5}}$ Recently, various Fe-based MOFs were synthesized and exhibited interesting properties. ${ }^{26-29}$ Especially, the employment of Fe-based MOFs as the catalysts for the direct $\mathrm{C}-\mathrm{H}$ bond activation showed excellent performance. ${ }^{30-33}$ On the other hand, studies using MOFs for benzene hydroxylation are rarely reported. Indeed, an example employing MIL-100(Fe) and MIL-68(Fe) for benzene hydroxylation showed less than $30.6 \%$ benzene conversion. ${ }^{34,35}$

With this in mind, we wish to report the synthesis and characterization of a new iron-based MOF, termed Fe-TBAPy. Structural analysis of Fe-TBAPy, formulated as $\mathrm{Fe}_{2}(\mathrm{OH})_{2}(-$ TBAPy) $4.4 \mathrm{H}_{2} \mathrm{O}$, revealed that Fe-TBAPy is built from $\left[\mathrm{Fe}(\mathrm{OH})\left(\mathrm{CO}_{2}\right)_{2}\right]_{\infty}$ rod-shaped SBUs linked by $\mathrm{TBAPy}^{4-}$ to form the frz topological framework. ${ }^{36}$ This structure is highlighted by $7 \AA$ channels along the $\mathrm{O}_{z}$ axis and $3.4 \AA$ pores sandwiching between the pyrene cores of $\mathrm{TBAPy}^{4-}$. With this feature, FeTBAPy was employed for benzene hydroxylation reaction. As 
a result, the catalysis reaction using 1.0 mol\% Fe-TBAPy proceeded with the optimized phenol yield and selectivity of $64.5 \%$ and $92.9 \%$, respectively. This value is higher than that of the other iron-based MOFs (e.g. MIL-100(Fe), MIL-126, MIL-68(Fe), MIL-88(Fe), and VNU-20) $)^{37-41}$ and comparable with those of the best-performing heterogeneous catalysts for benzene hydroxylation.

\section{Experimental}

\section{Chemicals}

$N, N$-Dimethylformamide (DMF), acetic acid $\left(\mathrm{CH}_{3} \mathrm{COOH}, 98 \%\right)$, dichloromethane $\left(\mathrm{CH}_{2} \mathrm{Cl}_{2}, 99.9 \%\right)$, and anhydrous methanol ( $\mathrm{MeOH}, 99.8 \%)$, were obtained from EMD Millipore Chemicals. Iron chloride anhydrous $\left(\mathrm{FeCl}_{2}, 98 \%\right)$ were obtained from Acros Organic. Palladium-tetrakis(triphenylphosphine) (99\%), benzene (99.9\%), toluene (99.8\%) $\mathrm{H}_{2} \mathrm{O}_{2} \quad(30$ wt $\%$ ) were purchased from Sigma-Aldrich. 1,3,6,8-tetrabromopyrene (purity $>98 \%$ ) and methyl 4-boronobenzoate (purity > 96\%) were purchased from Tokyo Chemical Industry Co. All starting materials and solvents were used without further purification. Fe-based MOFs and $\mathrm{H}_{4}$ TBAPy were synthesized according to the published procedures. ${ }^{37-42}$

\section{Synthesis of Fe-TBAPy}

A mixture of anhydrous $\mathrm{FeCl}_{2}(0.050 \mathrm{~g}, 0.39 \mathrm{mmol})$ and $\mathrm{H}_{4}$ TBAPy $(0.040 \mathrm{~g}, 0.058 \mathrm{mmol})$ was dissolved in $15 \mathrm{~mL}$ DMF. Subsequently, acetic acid $(250 \mu \mathrm{L})$ was added and the solution was sonicated for 5 minutes, divided into glass tubes $(1.5 \mathrm{~mL}$ each tube), which were flame-sealed under ambient atmosphere and temperature. Following this, the tubes were placed in an isothermal oven at $180{ }^{\circ} \mathrm{C}$ for one day. The resulting yellow micro-crystalline product was collected, washed with DMF (10 $\mathrm{mL})$, methanol $(10 \mathrm{~mL})$ and dichloromethane $(10 \mathrm{~mL})$ for $3 \mathrm{~d}$, respectively. During the solvent-exchange, each solvents were decanted and replenished 5 times per day. Finally, the product was evacuated under vacuum $\left(10^{-3}\right.$ torr $)$ at room temperature to yield Fe-TBAPy (67\% yield, based on $\mathrm{H}_{4}$ TBAPy). Elemental analysis (EA) of activated sample: calcd for $\mathrm{Fe}_{2} \mathrm{C}_{44} \mathrm{H}_{32.8} \mathrm{O}_{14.4}=$ $\mathrm{Fe}_{2}(\mathrm{OH})_{2}(\mathrm{TBAPy}) \cdot 4.4 \mathrm{H}_{2} \mathrm{O}: \mathrm{C}, 58.46 ; \mathrm{H}, 3.41 ; \mathrm{N}, 0 \%$. Found: C, 58.5; H, 3.69; N, 0.31\%. FT-IR (ATR): 1605 (m); 1580 (m); 1516 (m); 1380 (s); 1179 (m); 1144 (w); 1103 (w); 1019 (w); 1007 (m); $979(\mathrm{w}) ; 900(\mathrm{w}) ; 862(\mathrm{~m}) ; 742(\mathrm{~m}) ; 816(\mathrm{~m}) ; 784(\mathrm{~m}) ; 767(\mathrm{~m}) ;$ and 716 (m); 641 (m) (Fig. S5†).

\section{Results and discussion}

\section{Synthesis and characterization of Fe-TBAPy}

A mixture of $\mathrm{H}_{4}$ TBAPy and $\mathrm{FeCl}_{2}$ was dissolved in DMF in the presence of $\mathrm{CH}_{3} \mathrm{COOH}$ and isothermally heated at $180{ }^{\circ} \mathrm{C}$ for $24 \mathrm{~h}$ to yield yellow micro-crystalline material of Fe-TBAPy. The as-synthesized material was further collected, washed and activated under dynamic vacuum at room temperature. The PXRD pattern of the activated sample was collected and indexed (Fig. S2 $\dagger$ ). The resulted unit cell parameters were refined against the experimental profile by Pawley method. Accordingly, FeTBAPy is found to crystallize in the monoclinic space group, $P 2 / c$ (no. 13), with unit cell parameters, $a=14.2972 ; b=$ 15.5453; $c=14.0069 \AA$ and $\beta=84.79^{\circ}$ (Section $\mathrm{S} 4 \dagger$ ). We found that the obtained unit cell parameters are similar to that of the distorted structures of $\left[\operatorname{In}_{2}(\mathrm{OH})_{2}\right.$ (TBAPy) $] .^{42}$ Therefore, a modelled structure of Fe-TBAPy was built based on the atomic connectivity of $\left[\operatorname{In}_{2}(\mathrm{OH})_{2}(\mathrm{TBAPy})\right]$ (Table S1 $\dagger$ ). With this structural model, the full range Rietveld refinement against the experimental profile was performed to optimize the atom positions in the unit cell. Finally, the structure was successfully refined with low $R$-values $\left(2 \theta=2-80^{\circ}, R_{\mathrm{p}}=7.53 \%\right.$ and $R_{\mathrm{wp}}=$ $9.92 \%$, Fig. 2 and S3 $\dagger$ ). The refined structure clearly showed that Fe-TBAPy is built from the commonly observed $\left[\mathrm{Fe}(\mathrm{OH})\left(\mathrm{CO}_{2}\right)_{2}\right]_{\infty}$ rod-shaped SBUs (Fig. 1a), ${ }^{\mathbf{3 9 , 4 3 , 4 4}}$ which are connected by TBAPy $^{4-}$ linkers (Fig. 1b) to expand into the frz topological a)

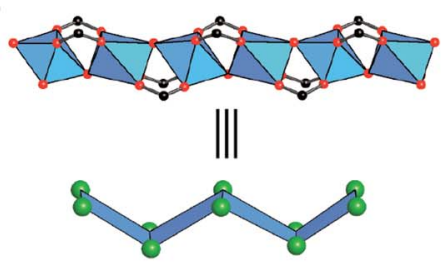

$\left[\mathrm{Fe}(\mathrm{OH})\left(\mathrm{CO}_{2}\right)_{2}\right]_{\infty}$

b)

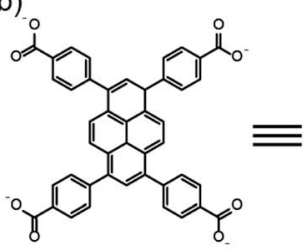

TBAPy-

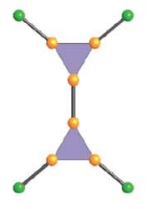

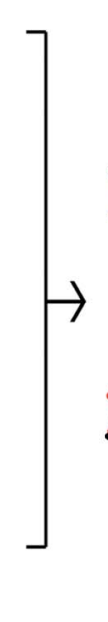

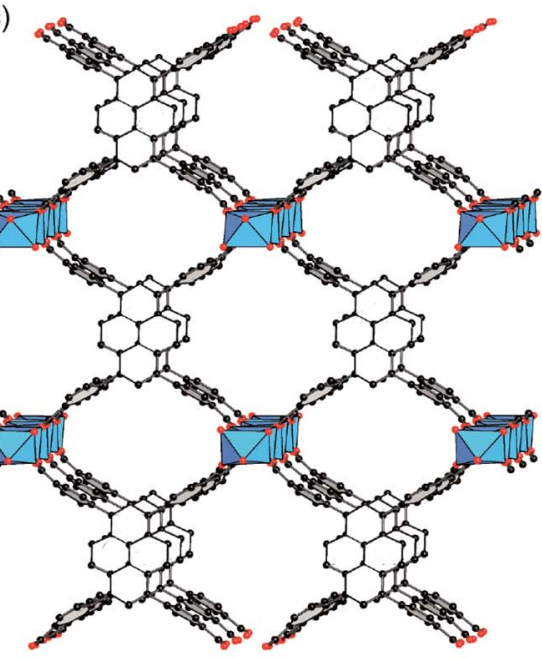

Fe-TBAPy

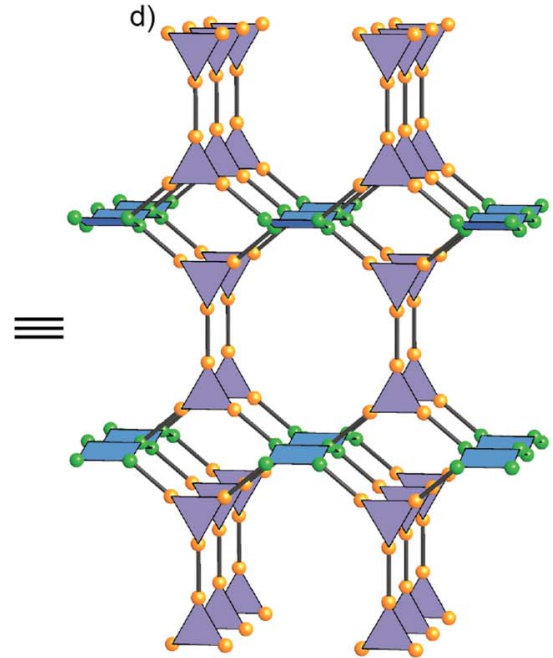

frz framework

Fig. 1 Fe-TBAPy is constructed from $\left[\mathrm{Fe}(\mathrm{OH})\left(\mathrm{CO}_{2}\right)_{2}\right]_{\infty}$ rod-shaped SBUs (a), linked by tetratopic TBAPy ${ }^{4-}$ linkers (b) to expand into the frz topologically based framework (c and d). Atom colors: Fe, blue polyhedra; C, black; O, red. All hydrogen atoms are omitted for clarity. 
framework (Fig. 1c and d) highlighted by $7 \AA$ channel and $3.4 \AA$ pores sandwiching between the pyrene cores of $\mathrm{TBAPy}^{4-}$ (Fig. S4†). ${ }^{45,46}$

Fourier transform-infrared (FT-IR) spectroscopy analysis of the activated sample showed the structural stability with the $\nu_{\mathrm{C}=\mathrm{O}}$ stretching peak of coordinated carboxylate at $1605 \mathrm{~cm}^{-1}$ (Fig. S5†). Elemental microanalysis (EA) confirmed the proposed chemical formula of Fe-TBAPy to be $\mathrm{Fe}_{2}(\mathrm{OH})_{2}$ (TBAPy) $4.4 \mathrm{H}_{2} \mathrm{O}: \mathrm{C}, 58.46 ; \mathrm{H}, 3.41 ; \mathrm{N}, 0 \%$. Found: C, 58.5; H, 3.69; N, $0.31 \%$. The thermal stability and the permanent porosity of $\mathrm{Fe}$ TBAPy were further investigated by thermogravimetric analysis (TGA) and $77 \mathrm{~K} \mathrm{~N}_{2}$ adsorption measurements. TGA showed that Fe-TBAPy is stable up to $300{ }^{\circ} \mathrm{C}$ with a small weight percentage loss $(<4.5 \mathrm{wt} \%)$ (Fig. S6 $\dagger$ ). Furthermore, the weight percentage of the residual oxide (assigned to $\mathrm{Fe}_{2} \mathrm{O}_{3}$ ) is $22.2 \mathrm{wt} \%$, which is consistent with the theoretical value calculated from the modelled structure (19.5 wt\%) (Fig. S6 $\dagger$ ). $\mathrm{N}_{2}$ isotherm of $\mathrm{Fe}$ TBAPy exhibits reversible uptake, with BET (Langmuir) surface area of $650 \mathrm{~m}^{2} \mathrm{~g}^{-1}\left(703 \mathrm{~m}^{2} \mathrm{~g}^{-1}\right)$ (Fig. S7 $\dagger$ ). These values are in agreement with the theoretically predicted surface area (Materials Studio 8.0; Langmuir $\mathrm{SA}=820 \mathrm{~m}^{2} \mathrm{~g}^{-1}$ ). Furthermore, pore size distribution analysis derived from $\mathrm{N}_{2}$ isotherm confirmed the existence of the $7 \AA$ channel in Fe-TBAPy (Fig. S8 $\dagger$ ).

Subsequently, the activated Fe-TBAPy were immersed in the water solution of $\mathrm{HCl}$ or $\mathrm{KOH}$ with $\mathrm{pH}$ from 2 to 10 for 5 days. Following this, these samples were exchanged with DMF, $\mathrm{MeOH}, \mathrm{CH}_{2} \mathrm{Cl}_{2}$, and activated under dynamic vacuum at room temperature. As shown in Fig. $S 9, \dagger$ the PXRD profile of the water-immersed samples showed the peak-shifts compared with the PXRD pattern of the activated sample. Further Pawley refinement against the experimental profile of these samples indicated the maintenance of the periodic structure; however, the slight changes of the unit cell parameters were found (Fig. S9†). Indeed, such structural flexibilities are also observed for $\left[\operatorname{In}_{2}(\mathrm{OH})_{2}(\mathrm{TBAPy})\right]$ and common Fe-based MOFs. ${ }^{42,43,47}$ FT-IR analysis of water-immersed samples also confirmed the

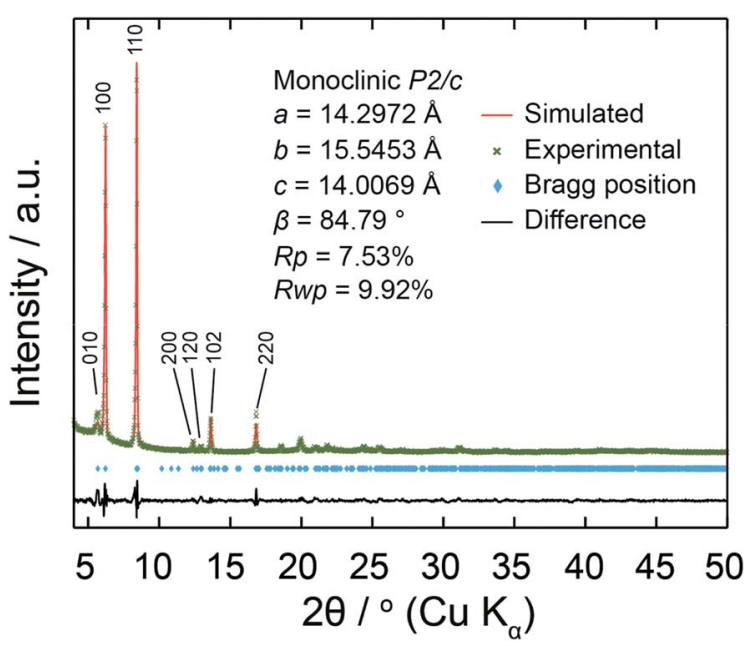

Fig. 2 Experimental (green) and refined (red) PXRD patterns of activated Fe-TBAPy after Rietveld refinement. The difference plot (black) and Bragg positions (blue) are also shown. Full range Rietveld refinement data $\left(2 \theta=2-80^{\circ}\right)$ is provided in the ESI (Section S4 $\uparrow$ ). maintenance of the coordinated bond with the characterized peak at $1605 \mathrm{~cm}^{-1}$ (Fig. S10†). Furthermore, the absence of peaks of free carboxylic acid implied the full maintenance of the atomic connectivity without exfoliation (Fig. S10†). This data showed that Fe-TBAPy is stable in acidic and basic water and such property endow this material to be employed as the oxidative catalyst under harsh conditions, in which common MOFs cannot retain the structure. ${ }^{48}$

\section{Catalytic activity}

Since the catalysis activity of MOFs strongly depends on the constituent metal SBUs ${ }^{\mathbf{4 1 , 4 9}}$ and/or the adsorption and diffusion of the substrates onto the internal surface, ${ }^{50,51}$ the materials, whose structures are characterized by substrate-fitting pores, tend to show the enhancing or selective catalysis. ${ }^{51-53}$ Inspired by $\mathrm{In}_{2}(\mathrm{OH})_{2}$ (TBAPy) compound, whose structure is found to allow the toluene molecules to sandwich into the narrow pores between the pyrene cores of $\mathrm{TBAPy}^{4-},{ }^{42}$ we anticipated that $3.4 \AA$ pores sandwiching inside Fe-TBAPy could be the strong adsorption-sites for benzene because of the strong $\pi-\pi$ interaction of this substrate and pyrene cores of $\mathrm{TBAPy}^{4-}$. This consequently boost the catalysis activity of Fe-TBAPy catalyst for the benzene hydroxylation reaction (Fig. S4 $\dagger$ ).

To take this further, the benzene hydroxylation reactions using Fe-TBAPy catalyst were evaluated according to a published procedure; however, with the slight modification of reaction parameters. ${ }^{34}$ Initially, the reaction was carried out at room temperature, in which the catalyst (4.3 mol\%), benzene $(50 \mu \mathrm{L})$ and $\mathrm{H}_{2} \mathrm{O}_{2}(30 \mathrm{wt} \%, 100 \mu \mathrm{L})$ were used. The reaction resulted in $36 \%$ GC yield for phenol after $24 \mathrm{~h}$ while the byproducts were not detected (Table S2, entry $1 \dagger$ ). Increasing the reaction temperature to $50{ }^{\circ} \mathrm{C}$ resulted in an increase of phenol yield to $40.1 \%$ with $94.5 \%$ selectivity found (Table S2, entry $2 \dagger$ ). In comparison, MIL-100(Fe) showed $30.6 \%$ benzene conversion after performing the catalysis reaction for $24 \mathrm{~h}$ (used equal mol\% of iron metal with Fe-TBAPy), ${ }^{34}$ the high phenol yield catalyzed by Fe-TBAPy, therefore, indicated the outperformed catalysis activity of Fe-TBAPy over MIL-100(Fe). We further carried out the catalysis reactions using $1 \mathrm{~mol} \% \mathrm{Fe}-$ TBAPy with increasing temperature and amount of $\mathrm{H}_{2} \mathrm{O}_{2}(100$, 300 and $600 \mu \mathrm{L}$ ) to maximize the performance of Fe-TBAPy. This resulted in the phenol yield of $17.9 \%, 33.9 \%$, and $57.8 \%$, respectively, at $70^{\circ} \mathrm{C}$ and $24 \mathrm{~h}$ (Fig. 3 and Table S2, entry 6, 7 and $8 \dagger)$. Extending the reaction time resulted in the steady increase of phenol yield until $33 \mathrm{~h}$ with 45.6 and $64.5 \%$ yield detected (corresponding to 300 and $600 \mu \mathrm{L} \mathrm{H}_{2} \mathrm{O}_{2}$, respectively) (Fig. 3 and Table S2, entry $9 \& 16 \dagger$ ). Interestingly, gas chromatography (GC) analysis showed the high phenol selectivity of $92.9 \%$ at the optimized condition (Fig. S11 and Table S2, entry $9 \dagger$ ). In addition, we found that the catalysis activity of Fe-TBAPy is comparable with that of the best-performing catalysts for benzene hydroxylation such as FeOCl $(43.5 \%),{ }^{1} \mathrm{~V}-\mathrm{Si}-\mathrm{ZSM}-22$ $(30.8 \%){ }^{3} \quad$ TS-1 (29.5\%), ${ }^{54} \quad$ PMO-1 $\quad(27.4 \%),{ }^{55} \quad \mathrm{Cu}_{2} \mathrm{O}-8 / \mathrm{dG}$ $(19.4 \%),{ }^{9} \mathrm{CuCr}_{2} \mathrm{O}_{4}^{\mathrm{RB}}(65 \%)^{5}$ (Table S3 $\dagger$ ).

The control experiment was further carried out to verify the heterogeneous nature of Fe-TBAPy. As expected, phenol 


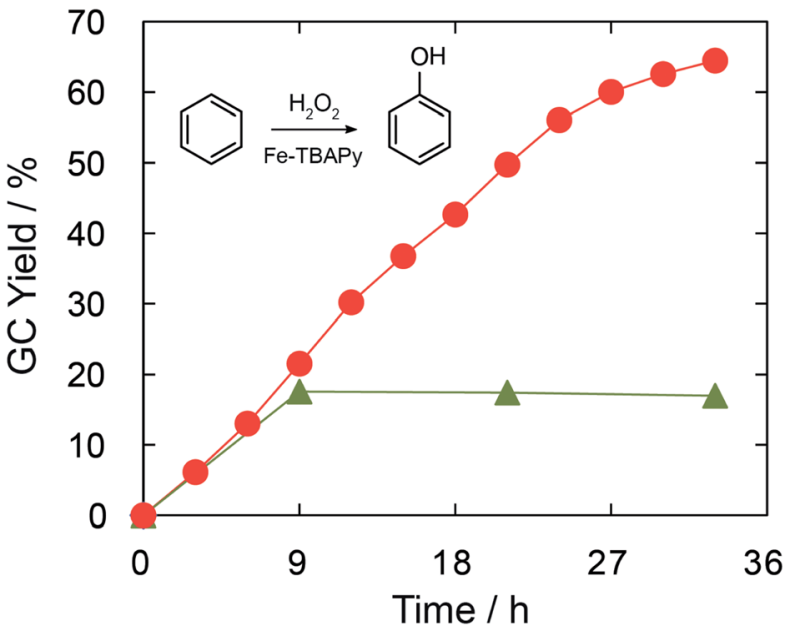

Fig. 3 GC yield of phenol in the presence of Fe-TBAPy catalyst (red cycle) and the control reaction with the removal of the catalyst after $9 \mathrm{~h}$ (green triangle).

formation was no longer detected after the isolation of FeTBAPy from the reaction medium. This implied the benzene hydroxylation reaction catalysed by Fe-TBAPy and the contribution of the iron metal leached out from Fe-TBAPy is negligible (Fig. 3). The durability of Fe-TBAPy as a catalyst was further evaluated by carrying out the catalysis experiments for up to five cycles. Experimental results indicated that Fe-TBAPy could be reused without a significant reduction in catalytic activity. Specifically, up to $60.9 \%$ GC yield of phenol was found after the fifth cycle using the recycled Fe-TBAPy sample (Fig. 4). Moreover, the structural maintenance without significant degradation of Fe-TBAPy after consecutive catalytic experiments was confirmed by FT-IR and PXRD measurements (Fig. S13 and $\mathrm{S} 14 \dagger)$.

The advantage of using Fe-TBAPy for benzene hydroxylation was further demonstrated by comparing the catalysis activity with the other Fe-based MOFs such as MIL-100(Fe) and MIL126, which are characterized by both the large pore and high surface area. ${ }^{37,38}$ As shown in Table 1 (entry $2 \& 3$ ), the catalysis

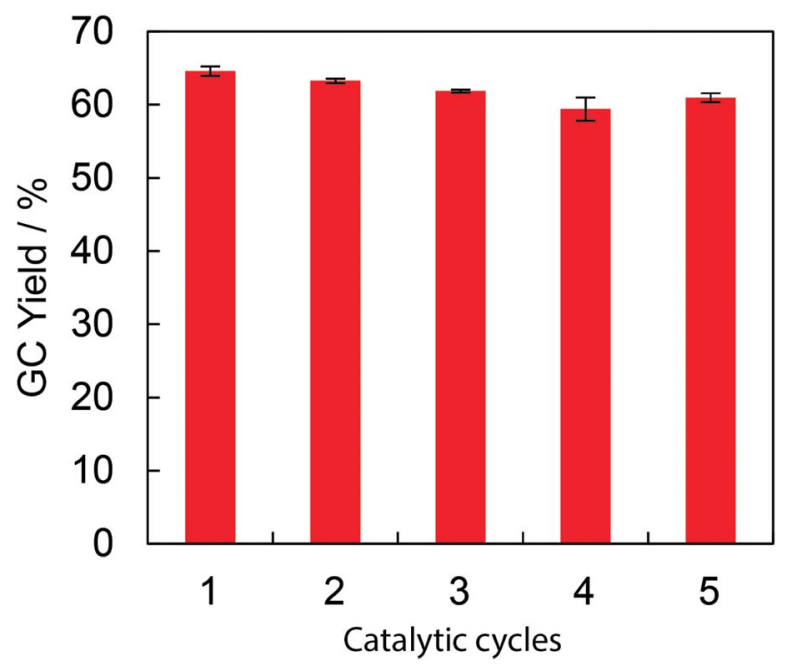

Fig. 4 Catalyst recycling studies of Fe-TBAPy.
Table 1 The hydroxylation of benzene performed in our laboratory utilizing different iron-based catalysts ${ }^{b}$

\begin{tabular}{llrl}
\hline Entry & Catalysts $^{c}$ & $Y_{\text {phenol }}{ }^{a} / \%$ & $S / \%$ \\
\hline 1 & Fe-TBAPy & $64.5 \pm 0.64$ & 92.9 \\
2 & MIL-100(Fe) & $45.3 \pm 1.67$ & 93.8 \\
3 & MIL-126 & $42.1 \pm 0.97$ & 93 \\
4 & VNU-20 & $48.1 \pm 1.22$ & 93.8 \\
5 & $\mathrm{MIL}-68(\mathrm{Fe})$ & $35.4 \pm 0.53$ & 91.6 \\
6 & $\mathrm{MIL}^{2} 88(\mathrm{Fe})$ & $38.2 \pm 1.27$ & 92.4 \\
7 & $\mathrm{FeCl}_{3} \cdot 6 \mathrm{H}_{2} \mathrm{O}$ & $5.9 \pm 0.43$ & 100 \\
8 & $\mathrm{FeCl}_{2}$ & $6.7 \pm 0.31$ & 100 \\
9 & $\mathrm{FeSO}_{4} \cdot 7 \mathrm{H}_{2} \mathrm{O}$ & $5.1 \pm 0.11$ & 100
\end{tabular}

${ }^{a} Y_{\text {phenol: }}$ GC yield of phenol; $S$ : phenol selectivity. ${ }^{b}$ Reaction conditions: benzene $(50 \mu \mathrm{L}), \mathrm{H}_{2} \mathrm{O}_{2}(30 \mathrm{wt} \%, 600 \mu \mathrm{L}), 70{ }^{\circ} \mathrm{C}$ and $33 \mathrm{~h}$. ${ }^{c}$ Equal mol\% $\mathrm{Fe}$ metal in each catalysts were used for comparison.

activity of Fe-TBAPy is significantly higher than those materials. We further synthesized and tested the catalysis activity of Febased MOFs constructed from the rod-shaped SBUs (e.g. MIL$68(\mathrm{Fe})$ and VNU-20). Accordingly, VNU-20 showed slightly lower catalysis activity comparing to Fe-TBAPy (Table 1, entry 4), whereas MIL-68(Fe) exhibited poor catalysis activity (Table 1, entry 5). Additionally, the catalysis reaction using MIL-88(Fe) and the homogeneous iron salts also showed poor performance (entry 6-9). Since Fe-based MOFs (MIL-100(Fe), MIL-126, and MIL-68(Fe)), whose structure are either characterized by large pore size and high surface area or built from the similar $\left[\mathrm{Fe}(\mathrm{OH})\left(\mathrm{CO}_{2}\right)_{2}\right]_{\infty}$ SBUs with Fe-TBAPy, ${ }^{39}$ showed poor catalysis activity, the high performance of Fe-TBAPy implied the presence of the narrow pores in Fe-TBAPy actually enhancing the catalysis activity of this material for benzene hydroxylation.

\section{Conclusions}

In summary, a new Fe-based MOF, termed Fe-TBAPy, is succeeded to synthesize and characterize. Structural analysis revealed that Fe-TBAPy is constructed from $\left[\mathrm{Fe}(\mathrm{OH})\left(\mathrm{CO}_{2}\right)_{2}\right]_{\infty}$ rod-shaped SBUs, which are linked by TBAPy ${ }^{4-}$ to extend into the three-dimensional frz topological framework. The structure of Fe-TBAPy is highlighted by $7 \AA$ channel and $3.4 \AA$ pores sandwiching between the pyrene cores of $\mathrm{TBAPy}^{4-}$. With this structural feature, Fe-TBAPy was employed as the catalyst for hydroxylation of benzene. The catalytic tests resulted in the optimized phenol yield and selectivity of $64.5 \%$ with $92.9 \%$, respectively. Remarkably, this value is found to be higher than that of iron-based MOFs (e.g. MIL-100(Fe), MIL-126, MIL-68(Fe), MIL-88(Fe) and VNU-20) and comparable with that of the bestperforming catalysts for benzene hydroxylation. We believe that this experience will inspire the design and synthesis of new porous frameworks, for examples, via the reticular expansion or mixed metals approach to maximize the catalysis performance for benzene hydroxylation. ${ }^{56,57}$

\section{Conflicts of interest}

There are no conflicts to declare. 


\section{Acknowledgements}

We are grateful to Prof. Omar M. Yaghi (UC Berkeley) for the continued support for global science initiatives. This studies were financially supported by the Vietnam National Foundation for Science and Technology Development (NAFOSTED) under Project code 104.05-2018.365. We thank Thuy B. T. Le, Huy Q. Tran at HCMUTE for their assistance with this work.

\section{References}

1 A. E. ElMetwally, G. Eshaq, F. Z. Yehia, A. M. Al-Sabagh and S. Kegnæs, ACS Catal., 2018, 8, 10668-10675.

2 S. S. Acharyya, S. Ghosh, R. Tiwari, C. Pendem, T. Sasaki and R. Bal, ACS Catal., 2015, 5, 2850-2858.

3 Y. Zhou, Z. Ma, J. Tang, N. Yan, Y. Du, S. Xi, K. Wang, W. Zhang, H. Wen and J. Wang, Nat. Commun., 2018, 9, 2931-2941.

4 H. Wang, C. Wang, M. Zhao, Y. Yang, L. Fang and Y. Wang, Chem. Eng. Sci., 2018, 177, 399-409.

5 S. S. Acharyya, S. Ghosh and R. Bal, ACS Appl. Mater. Interfaces, 2014, 6, 14451-14459.

6 T. Jiang, W. Wang and B. Han, New J. Chem., 2013, 37, 16541664.

7 P. Borah, A. Datta, K. T. Nguyen and Y. Zhao, Green Chem., 2016, 18, 397-401.

8 M. Shahami, K. M. Dooley and D. F. Shantz, J. Catal., 2018, 368, 354-364.

9 J. He, M. Zhang, A. Primo, H. García and Z. Li, J. Mater. Chem. A, 2018, 6, 19782-19787.

10 T. Zhang, D. Zhang, X. Han, T. Dong, X. Guo, C. Song, R. Si, W. Liu, Y. Liu and Z. Zhao, J. Am. Chem. Soc., 2018, 140, 16936-16940.

11 V. I. Pârvulescu, D. Dumitriu and G. Poncelet, J. Mol. Catal. A: Chem., 1999, 140, 91-105.

12 H. Furukawa, K. E. Cordova, M. O'Keeffe and O. M. Yaghi, Science, 2013, 341, 1230444, DOI: 10.1126/science.1230444.

13 K. Adil, Y. Belmabkhout, R. S. Pillai, A. Cadiau, P. M. Bhatt, A. H. Assen, G. Maurin and M. Eddaoudi, Chem. Soc. Rev., 2017, 46, 3402-3430.

14 H. Furukawa, F. Gándara, Y.-B. Zhang, J. Jiang, W. L. Queen, M. R. Hudson and O. M. Yaghi, J. Am. Chem. Soc., 2014, 136, 4369-4381.

15 C. A. Rowland, G. R. Lorzing, E. J. Gosselin, B. A. Trump, G. P. A. Yap, C. M. Brown and E. D. Bloch, J. Am. Chem. Soc., 2018, 140, 11153-11157.

16 X. Meng, H.-N. Wang, S.-Y. Song and H.-J. Zhang, Chem. Soc. Rev., 2017, 46, 464-480.

17 M. V. Nguyen, T. H. N. Lo, L. C. Luu, H. T. T. Nguyen and T. N. Tu, J. Mater. Chem. A, 2018, 6, 1816-1821.

18 T. H. N. Lo, M. V. Nguyen and T. N. Tu, Inorg. Chem. Front., 2017, 4, 1509-1516.

19 K. G. M. Laurier, F. Vermoortele, R. Ameloot, D. E. De Vos, J. Hofkens and M. B. J. Roeffaers, J. Am. Chem. Soc., 2013, 135, 14488-14491.
20 T. N. Tu, M. V. Nguyen, H. L. Nguyen, B. Yuliarto, K. E. Cordova and S. Demir, Coord. Chem. Rev., 2018, 364, 33-50.

21 L. E. Kreno, K. Leong, O. K. Farha, M. Allendorf, R. P. V. Duyne and J. T. Hupp, Chem. Rev., 2012, 112, 1105-1125.

22 Z. Sun, S. Yu, L. Zhao, J. Wang, Z. Li and G. Li, Chem. - Eur. J., 2018, 24, 10829-10839.

23 L. Yang, C. Lian, X. Li, Y. Han, L. Yang, T. Cai and C. Shao, ACS Appl. Mater. Interfaces, 2017, 9, 17208-17217.

24 S. Wuttke, M. Lismont, A. Escudero, B. Rungtaweevoranit and W. J. Parak, Biomaterials, 2017, 123, 172-183.

25 R. Freund, U. Lächelt, T. Gruber, B. Rühle and S. Wuttke, ACS Nano, 2018, 12, 2094-2105.

26 Z. R. Herm, B. M. Wiers, J. A. Mason, J. M. van Baten, M. R. Hudson, P. Zajdel, C. M. Brown, N. Masciocchi, R. Krishna and J. R. Long, Science, 2013, 340, 960-964.

27 J. A. Mason, J. Oktawiec, M. K. Taylor, M. R. Hudson, J. Rodriguez, J. E. Bachman, M. I. Gonzalez, A. Cervellino, A. Guagliardi, C. M. Brown, P. L. Llewellyn, N. Masciocchi and J. R. Long, Nature, 2015, 527, 357-361.

28 T. N. Tu, N. Q. Phan, T. T. Vu, H. L. Nguyen, K. E. Cordova and H. Furukawa, J. Mater. Chem. A, 2016, 4, 3638-3641.

29 T. A. To, Y. H. Vo, H. T. T. Nguyen, P. T. M. Ha, S. H. Doan, T. L. H. Doan, S. Li, H. V. Le, T. N. Tu and N. T. S. Phan, J. Catal., 2019, 370, 11-20.

30 D. J. Xiao, E. D. Bloch, J. A. Mason, W. L. Queen, M. R. Hudson, N. Planas, J. Borycz, A. L. Dzubak, P. Verma, K. Lee, F. Bonino, V. Crocella, J. Yano, S. Bordiga, D. G. Truhlar, L. Gagliardi, C. M. Brown and J. R. Long, Nat. Chem., 2014, 6, 590-595.

31 D. J. Xiao, J. Oktawiec, P. J. Milner and J. R. Long, J. Am. Chem. Soc., 2016, 138, 14371-14379.

32 S. H. Doan, V. H. H. Nguyen, T. H. Nguyen, P. H. Pham, N. N. Nguyen, A. N. Q. Phan, T. N. Tu and N. T. S. Phan, RSC Adv., 2018, 8, 10736-10745.

33 S. H. Doan, N. K. Q. Tran, P. H. Pham, V. H. H. Nguyen, N. N. Nguyen, P. T. M. Ha, S. Li, H. V. Le, N. T. H. Le, T. N. Tu and N. T. S. Phan, Eur. J. Org. Chem., 2019, 2019, 2382-2389.

34 D. Wang, M. Wang and Z. Li, ACS Catal., 2015, 5, 6852-6857. 35 B. Xu, Z. Chen, B. Han and C. Li, Catal. Commun., 2017, 98, 112-115.

36 M. O'Keeffe, M. A. Peskov, S. J. Ramsden and O. M. Yaghi, Acc. Chem. Res., 2008, 41, 1782-1789.

37 P. Horcajada, S. Surblé, C. Serre, D.-Y. Hong, Y.-K. Seo, J.-S. Chang, J.-M. Grenèche, I. Margiolaki and G. Férey, Chem. Commun., 2007, 2820-2822.

38 M. Dan-Hardi, H. Chevreau, T. Devic, P. Horcajada, G. Maurin, G. Férey, D. Popov, C. Riekel, S. Wuttke, J.-C. Lavalley, A. Vimont, T. Boudewijns, D. de Vos and C. Serre, Chem. Mater., 2012, 24, 2486-2492.

39 A. Fateeva, P. Horcajada, T. Devic, C. Serre, J. Marrot, J. M. Grenèche, M. Morcrette, J. M. Tarascon, G. Maurin and G. Férey, Eur. J. Inorg. Chem., 2010, 68, 3789-3794.

40 S. Surblé, C. Serre, C. Mellot-Draznieks, F. Millange and G. Férey, Chem. Commun., 2006, 284-286. 
41 P. H. Pham, S. H. Doan, H. T. T. Tran, N. N. Nguyen, A. N. Q. Phan, H. V. Le, T. N. Tu and N. T. S. Phan, Catal. Sci. Technol., 2018, 8, 1267-1271.

42 K. C. Stylianou, R. Heck, S. Y. Chong, J. Bacsa, J. T. A. Jones, Y. Z. Khimyak, D. Bradshaw and M. J. Rosseinsky, J. Am. Chem. Soc., 2010, 132, 4119-4130.

43 P. L. Llewellyn, P. Horcajada, G. Maurin, T. Devic, N. Rosenbach, S. Bourrelly, C. Serre, D. Vincent, S. LoeraSerna, Y. Filinchuk and G. Férey, J. Am. Chem. Soc., 2009, 131, 13002-13008.

44 S. Bourrelly, P. L. Llewellyn, C. Serre, F. Millange, T. Loiseau and G. Férey, J. Am. Chem. Soc., 2005, 127, 13519-13521.

45 R. J. Li, M. Li, X. P. Zhou, D. Li and M. O'Keeffe, Chem. Commun., 2014, 50, 4047-4049.

46 A. Schoedel, M. Li, D. Li, M. O'Keeffe and O. M. Yaghi, Chem. Rev., 2016, 116, 12466-12535.

47 S. Surble, C. Serre, C. Mellot-Draznieks, F. Millange and G. Ferey, Chem. Commun., 2006, 284-286.

48 A. J. Howarth, Y. Liu, P. Li, Z. Li, T. C. Wang, J. T. Hupp and O. K. Farha, Nat. Rev. Mater., 2016, 1, 15018-15033.
49 Y.-B. Huang, J. Liang, X.-S. Wang and R. Cao, Chem. Soc. Rev., 2017, 46, 126-157.

50 H. T. T. Nguyen, T. N. Tu, M. V. Nguyen, T. H. N. Lo, H. Furukawa, N. N. Nguyen and M. D. Nguyen, ACS Appl. Mater. Interfaces, 2018, 10, 35462-35468.

51 J. M. Roberts, B. M. Fini, A. A. Sarjeant, O. K. Farha, J. T. Hupp and K. a Scheidt, J. Am. Chem. Soc., 2012, 134, 3334-3337.

52 H. Fei, D. L. Rogow and S. R. J. Oliver, J. Am. Chem. Soc., 2010, 132, 7202-7209.

53 W. Zhang, G. Lu, C. Cui, Y. Liu, S. Li, W. Yan, C. Xing, Y. R. Chi, Y. Yang and F. Huo, Adv. Mater., 2014, 26, 40564060.

54 P. T. Tanev, M. Chibwe and T. J. Pinnavaia, Nature, 1994, 368, 321-323.

55 P. Borah, X. Ma, K. T. Nguyen and Y. Zhao, Angew. Chem., Int. Ed., 2012, 51, 7756-7761.

56 H. Furukawa, U. Müller and O. M. Yaghi, Angew. Chem., Int. Ed., 2015, 54, 3417-3430.

57 L. J. Wang, H. Deng, H. Furukawa, F. Gándara, K. E. Cordova, D. Peri and O. M. Yaghi, Inorg. Chem., 2014, 53, 5881-5883. 